development of the field or fields concerned. In view of the amount of information in each, and its importance, their prices are not excessive.

W. R. MOORE

\section{MASS SPECTRA OF ORGANIC COMPOUNDS}

Interpretation of Mass Spectra of Organic Compounds By Dr. Herbert Budzikiewicz, Prof. Carl Djerassi and Dr. Dudley H. Williams. Pp. xiii +271 . (San Francisco: Holden-Day, Inc., 1964.) 8.75 dollars.

ALL laboratories of reasonably advanced organic A chemistry now have equipment for the determination of ultra-violet and infra-red spectra and many have nuclear magnetic resonance spectrometers, the cost of the machine and its subsequent maintenance being, of course, the limiting factor. Comparatively few labora. tories in Britain have modern mass spectrometers, although the number of laboratories so equipped will certainly increase as fast as funds permit. The mass spectrometer has many uses, but its prime use to the organic chemist is the information regarding chemical structure which it so readily and effectively supplies: this use was first appreciated and applied on any considerable scale by petroleum chemists, but the appreciation is now widely increasing.

It is noteworthy that books on modern mass spectrometry, cited by the authors of Interpretation of Mass Spectra of Organic Compounds, number only seven, the first being Dr. J. H. Beynon's Mass Spectrometry and its Applications to Organic Chemistry, which appeared in 1960 and which the authors of the present book justly describe as a classic. Prof. Djerassi and his colleagues consider that the many facets of mass spectrometry dealt with in these books, such as instrumentation, sample handling, free radicals and ionization potentials, analytical applications, etc., need not be repeated in the present volume, which deals almost exclusively with the determination of organic structure, and with the spectral fragmentation of organic compounds, which is, of course, an intimate part of the structure elucidation. Aliphatic hydrocarbons are not included, because they are dealt with adequately in the earlier books and are not of general interest to 'structural' organic chemists.

The book considers first the simple and common functional groups, such as the carbonyl, hydroxyl and amino functions, and discusses the fragmentation processes initiated by them on electron impact. The generalizations so obtained are then illustrated by their application to the tropane alkaloids, which have three such groups attached to a small alicyclic framework. Other classes of comparatively simple organic molecules are then considered. A second volume will later deal with more complex polycyclic compounds, particularly those of natural occurrence.

It is also noteworthy that much of the material in the present volume has been published very recently or is still unpublished, and the book contains therefore the latest relevant results obtained in Prof. Djerassi's very vigorous school of research at Stanford.

In a preliminary "Note to the Reader", the authors have attempted "as precise a definition as possible of the different bond fissions and transfer reactions", and they make some refreshingly direct statements. "Standard organic chemical concepts . . . are so readily applicable to the interpretation of mass spectrometric fragmentation processes that a certain sloppiness in symbolism has crept into most of the recent literature." Then after a common example of mechanism, they add that this representation "implies the shift of a proton, which very probably does not bear any resemblance to reality". This 'gloppiness in symbolism' (being, of course, the outward expression of an inner sloppiness of thought) is common in many branches of organic chemistry, and it is heartening to know that the authors will have none of it.

This volume can be strongly recommended to chemists as a clear yet thorough introduction to this branch of mass spectrometry.

F. G. MaNN

\section{GAS KINETICS}

\section{Experimental Methods in Gas Reactions}

Second edition. By Sir Harry Melville and B. G. Gowen. lock. Pp. viii + 464. (London: Macmillan and Co., Ltd.; New York: St. Martin's Press, Inc., 1964.) 84s.

$T$ HE original edition of this book achieved a unique position among research workers in Britain as a source of information on practical experimental methods in gas kinetics that was often difficult to find. Much of its success was undoubtedly due to the exceptional experimental ability of its two authors, whose personality and outlook pervade the whole text.

To revise such a personal work requires considerable courage even when done by the original authors, as the impact of the experimental scientist is usually one of the first casualties in the war against time. The second edition has, however, been revised by a newcomer, admittedly under the guidance of Sir Harry Melville, but unfortunately he has left the manostat and explosion vessel a fair way behind. Perhaps inevitably the book loses something of its flavour, and the somewhat untidy bittiness of its approach, which seemed an essential part of the character of the old volume, now, accentuated by the process of selection and addition necessary to include contemporary material, tempts one to suggest that it might have been better to start afresh.

As the preface to the second edition points out, "Farkas and Melville" has been out of print since 1946 and many. of the younger generation of experimentalists may well be not very familiar with it. (I was a little disconcerted. to find that in our own library both copies have now been relegated to the reserve stock dungeons.) For this reason perhaps it is only fair to comment on the present edition on its own merits.

Following a useful introductory chapter on the kinetic theory of gases, a wide variety of practical apparatus and methods for the measurement and control of pressure and temperature are considered. The simple feed-back circuit for the constant temperature operation of Pirani gauges on p. 90 seems a happy intrusion into the vacuum field from high-speed anemometer practice and might well be. extended to provide fast respoinse katharometers for gas chromatography. The acoustic pump mentioned on p. 53 deserves more attention than it has received. There are some areas where the treatment given is scarcely adequate to do anything useful, such as the very brief discussion of thermistors, but a good range of references is provided. Occasionally, important omissions are obvious as, for example, in the gas control section where the use of critical flow orifices for flow control (for small flows watch bearings are very suitable) is not mentioned.

The chapter on preparation of gases and volatile compounds is excellent and contains a wealth of material which it would be quite laborious to find from other sources. However, in the next chapter, in spite of the authors' comment in the preface, the emphasis on the older methods of gas analysis at the expense of gas chromatography seems incongruous in the light of the fact that the latter has displaced almost every other method. Although a useful survey of most aspects of this important method is given, the treatment is so compressed: that it can be misleading. For example, the flame. thermocouple detector, which even R. P. W. Scott would recognize as obsolescent, is given undue emphasis, while the difficulties of achieving high sensitivity for permanent. gases using ionization methods are not mentioned. 